\title{
A FUNÇÃO INTERPESSOAL NO ENTENDIMENTO DA MODALIDADE DEÔNTICA
}

\author{
LA FUNCIÓN INTERPERSONAL EN EL ENTENDIMIENTO DE LA MODALIDAD DEÓNTICA \\ INTERPERSONAL FUNCTION IN THE UNDERSTANDING OF DEONTIC MODAL
}

\author{
Léia Cruz Menezes* \\ Universidade Federal do Ceará - UFC, Fortaleza, BR
}

\begin{abstract}
RESUMO: Neste artigo, procedemos à reflexão sobre a não contemplação da função interpessoal no entendimento do subtipo modal deôntico na Gramática Funcional (GF) e na Gramática Discursivo-Funcional (GDF). Consideramos como a modalidade deôntica é tratada no arcabouço da GF; na sequência, ponderamos acerca da proposta de Verstraete (2004) para o entendimento da modalidade deôntica em função interpessoal; em seguida, expomos como a modalidade deôntica foi entendida na GDF; por fim, por meio de um cotejo entre a GDF e a Gramática Sistêmico-Funcional (GSF), arrematamos com nossa reflexão acerca do sentido do termo "funcional" subjacente à GF e à GDF.

PALAVRAS-CHAVE: Modalidade deôntica; Função interpessoal; Gramática Funcional; Gramática Discursivo-Funcional.
\end{abstract}

RESUMEN: En este artículo, procedemos a la reflexión sobre la no contemplación de la función interpersonal en el entendimiento del subtipo modal deóntico en la Gramática Funcional (GF) y en la Gramática Discursivo-Funcional (GDF). Consideramos cómo la modalidad deóntica es tratada en el marco de la GF; seguidamente, reflexionamos acerca de la propuesta de Verstraete (2004) para el entendimiento de la modalidad deóntica en función interpersonal; en seguida, demostramos cómo la modalidad deóntica fue entendida en la GDF; por fin, por medio de una aproximación entre la GDF y la Gramática Sistémico-Funcional (GSF), arrematamos con nuestra reflexión acerca del sentido del termo "funcional" que subyace a la GF y a la GDF.

PALABRAS-CLAVE: Modalidad deóntica; Función interpersonal; Gramática Funcional; Gramática Discursivo-Funcional.

ABSTRACT: In this article, we continue our reflection over the interpersonal function not contemplation in the understanding of deontic modal subtype in the Functional Grammar (GF) and in the Discursive-Functional Grammar (GDF). It will be considered how the deontic modality is treated in the framework of the GF; afterwards, the Vertraete's proposal (2004) will be pondered for the understanding of the deontic modality in interpersonal function; then, it will be exposed how the understanding of the deontic modality happened in the GDF; finally, through a comparison between the GDF and the Systemic-Functional Grammar (GSF), we will finish our reflection over the meaning of the term "functional" underlying both GF and GDF.

KEYWORDS: Deontic modality; Interpersonal function; Functional Grammar; Discursive-Functional Grammar.

\section{NOTA INTRODUTÓRIA}

Embora se distingam peculiaridades que tornam os diferentes modelos funcionalistas distintos entre si, em linhas gerais, compreende-se a denominação "gramática funcional" como uma teoria global da interação social que prioriza a análise das funções das unidades linguísticas sobre seus limites e sua posição e que concebe a gramática como sensível às pressões dos usos. Assim o é porque, segundo depreendemos de Dik (1997a, p.1-2), a orientação funcionalista entende que, no uso comunicativo da língua, não apenas a capacidade linguística está envolvida. Juntamente a essa capacidade, atuam outras, a saber: a epistêmica, a lógica, a perceptual, a social.

Conforme destaca Neves (1997), em decorrência da capacidade epistêmica, o usuário é capaz de construir, manter e explorar uma base de conhecimento organizado, derivar conhecimentos de expressões linguísticas, arquivar esse conhecimento adequadamente e, nas situações de intercâmbio linguístico, recuperá-lo e utilizá-lo, possibilitando a interpretação de expressões linguísticas em situações posteriores. A capacidade lógica, por sua vez, possibilita ao usuário, munido de determinadas parcelas de conhecimento, a extração de outras parcelas de conhecimento mediante regras de raciocínio. Em virtude da capacidade perceptual, o usuário extrai, da percepção do meio que o cerca, conhecimento para produzir e interpretar expressões linguísticas. Devido à capacidade social, o usuário não apenas sabe o que dizer, mas como e de que modo

\footnotetext{
*Email: leialinguistica@ig.com.br.
} 
expressar-se em uma situação comunicativa específica. Essas diferentes capacidades não atuam isoladamente, mas imbricam-se, produzindo, cada uma, um output essencial ao funcionamento das demais.

A orientação funcionalista distingue-se da formalista na medida em que define a língua como atividade cooperativa e estruturada, cuja função mais destacada é a de agir sobre o outro. E, se, no mecanismo de uso da língua em situações reais de intercâmbio linguístico, várias e diversas são as capacidades dos usuários que interagem possibilitando a comunicação, não há como conceber uma descrição das expressões de uma língua de modo descontextualizado. A descrição das expressões deve fornecer dados para a explicação de seu modo de atuação em contexto específico.

Com base nesses postulados centrais, que costumam ser enunciados na caracterização da perspectiva linguística funcionalista, intriga-nos a não contemplação da função interpessoal no entendimento do subtipo modal deôntico em dois importantes modelos de descrição linguística funcionalista: a Gramática Funcional (GF) e a Gramática Discursivo-Funcional (GDF). Se a abordagem funcionalista busca explicar as construções das expressões linguísticas em termos de sua funcionalidade em relação aos modos de utilização das expressões, como podem os dois referidos modelos situar expressões modais deônticas em nível apenas representacional (leia-se em nível apenas semântico, não pragmático)?

Tanto na GF quanto na GDF os subtipos modais são compreendidos como modificadores de conteúdos de vários níveis: alguns recaem sobre o nível proposicional (interpessoal), outros sobre o nível da descrição de um estado-de-coisas (representacional) etc. O subtipo modal deôntico, no qual centramos aqui especial atenção, concerne à necessidade e à possibilidade de que os atos sob seu escopo sejam executados por agentes. Esse subtipo modal é entendido como situado no eixo conceptual da conduta e associado às funções sociais de obrigação e permissão. Tanto na GF quanto na GDF seu escopo é funcionalmente semântico, não pragmático, daí, funcionalmente, não interpessoal. Aqui registramos que essa separação entre o semântico e o pragmático não é ponto pacífico na seara do pensamento linguístico que visa à descrição de unidades linguísticas que contemple aspectos discursivos.

A fim de refletirmos sobre a não contemplação da função interpessoal no entendimento da modalidade deôntica na GF e na GDF, seguiremos a seguinte linha de raciocínio: no primeiro momento, consideramos como a modalidade deôntica é tratada no arcabouço teórico-metodológico da GF (1997); na sequência, ponderamos acerca da proposta de Vestraete (2004) para o entendimento da modalidade deôntica em função interpessoal dentro do modelo da GF; em seguida, consideramos como a modalidade deôntica foi entendida no arcabouço da GDF (2008); por fim, arrematamos o texto com nossa reflexão acerca do sentido do termo "funcional" que alicerça os dois supracitados modelos a partir da acepção de "funcional" constante na Gramática Sistêmico-Funcional (2004 [1985]). Entendemos que a compreensão dos modais deônticos em usos linguísticos reais precisa contemplar o escopo interpessoal tendo em vista que o valor deôntico é fortemente dependente do papel que os interactantes assumem na interlocução. (MENEZES, 2011, 2006).

\section{A MODALIDADE DEÔNTICA SOB O PRISMA DA GRAMÁTICA FUNCIONAL (GF)}

O modelo de Gramática Funcional proposto por Dik (1997), com foco na gramática da oração, apresenta como ponto de destaque a representação formal dos enunciados. Para entendermos a tipologia da categoria modalidade nessa perspectiva funcional, faz-se necessária a compreensão da representação da oração em camadas segundo proposição do autor.

Dik parte do pressuposto de que qualquer texto numa língua natural pode ser exaustivamente dividido em dois tipos de constituintes: os que pertencem às orações e os que a elas não pertencem, os chamados constituintes extraoracionais. Constituintes extraoracionais são, portanto, os situados fora do âmbito da oração. Em uma construção como (1) "Bem, João, eu acredito que seu tempo acabou." , os constituintes bem (um "Iniciador") e João (um "Destinatário” ou "Vocativo") são extraoracionais. Por sua vez, eu acredito que seu tempo acabou é a oração principal, e que seu tempo acabou é a oração subordinada.

1 "Well, Jonh, I belive that your time is up." (DIK, 1997a, p.49). 
A fim de descrever as propriedades formais e semânticas das orações de um modo tipologicamente adequado, Dik assume que cada oração deve ser descrita em termos de uma estrutura abstrata subjacente. Trata-se de uma estrutura complexa, pois, nela, são distinguidos vários níveis de organização semântica e formal. Essa estrutura é assim apresentada na obra do pesquisador:

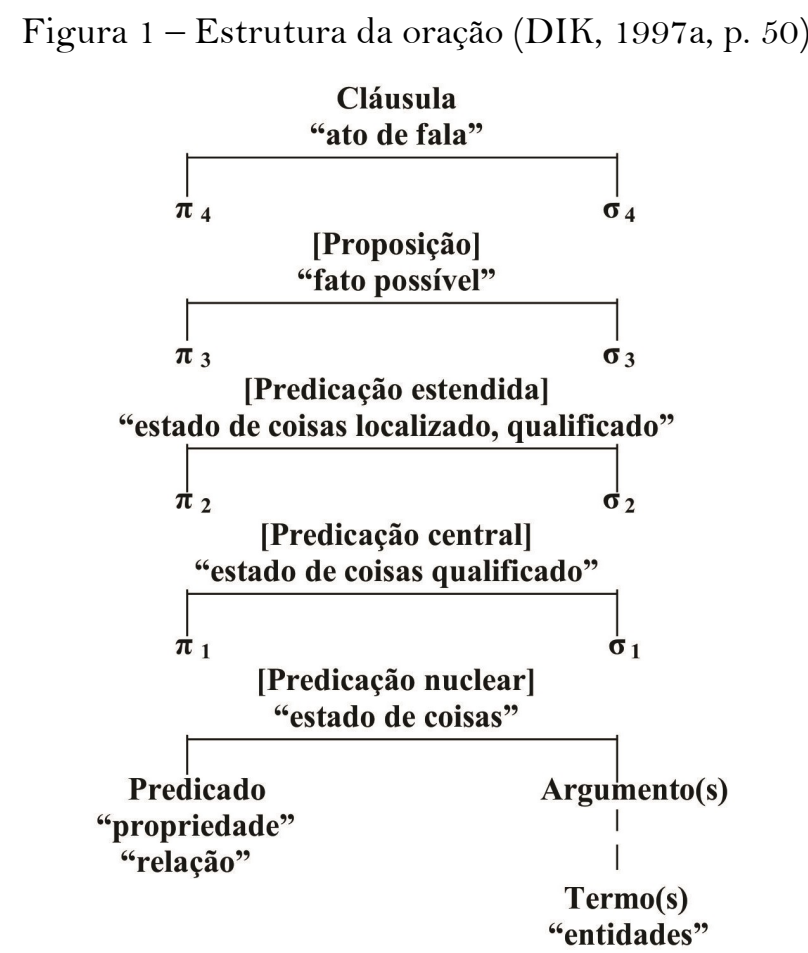

Antes de comentarmos o modelo esboçado na figura 1, faz-se imprescindível destacar seu caráter não transformacional e sua não intenção quanto a dar conta do correlato psicológico da produção linguística. $\mathrm{O}$ próprio Dik (1997a, p.57-58), ciente das limitações de seu modelo, no que concerne a flagrar o modo como a produção linguística transcorre em termos psicológicos, manifesta-se acerca da sequencialidade de etapas que concorrem à produção de enunciados nos seguintes termos:

A ordem de produção real não é nem mesmo necessariamente organizada de modo sequencial. Estudos psicológicos de produção (e interpretação!) de sentenças tornam plausível que os usuários das línguas naturais tenham antes fortes capacidades para o processamento paralelo de informação. Isso significa que uma parte do aparato de produção do falante pode estar operante na construção de termos, enquanto outra está procurando por predicados satisfatórios, e uma terceira está ativa para a decisão de qual deve ser a força ilocucionária. ${ }^{2}$

Após conceder ao leitor o que chama de "primeira apresentação dessa estrutura", aqui reproduzida na figura 01, Dik passa a descrever esse modelo abstrato da oração no sentido ascendente, isto é, a partir das unidades lexicais. A estrutura da oração subjacente, explica Dik, requer, em primeira instância, um predicado, ao qual será adicionado um número de termos de tipos apropriados, os quais funcionarão como argumentos do predicado. Enquanto os predicados designam propriedades ou relações, os termos são usados em referência a entidades. Como exemplo de um predicado, Dik (1997, p.50) se vale do verbo escrever (write). Esse predicado comporta dois argumentos, ou dois lugares, os quais designam uma relação entre duas entidades, uma no papel de 'quem escreve' e a outra no papel de 'alguma coisa escrita', que são preenchidos por dois termos, por exemplo, João (John) e a carta (a letter). Quando um predicado é preenchido por um tipo apropriado de termos, o resultado é a obtenção da predicação nuclear. Nesse exemplo, prossegue Dik, a predicação nuclear resultante pode ser representada em uma construção como (2) "escrever (João) (uma carta)". ${ }^{3}$

\footnotetext{
2 "The order of actual production is not even necessarily in a sequential way. Psychological studies of sentence production (an interpretation!) make it plausible that natural language users have rather strong capacities for the parallel processing of information. This means that one section of the speaker's production facility may be working on the construction of terms, while another section is already looking around for suitable predicates, and a third section is active in deciding what the illocutionary force is going to be." (DIK, 1997a, p.57-58).

3 “write (Jonh) (a letter)". (DIK, 1997a, p.5 1)
} 
Tal predicação nuclear pode ser interpretada como designativa de um tipo de estado de coisas, o qual é entendido como "a concepção de alguma coisa que pode ocorrer em algum mundo". Se assumirmos a existência de um mundo no qual uma pessoa chamada 'João' escreve alguma coisa que se possa chamar de 'carta', então podemos dizer que a construção citada no parágrafo anterior descreve corretamente esse estado de coisas neste mundo. Destaca Dik que um estado de coisas não precisa necessariamente existir ou acontecer na "realidade" para ser designado por uma predicação: o estado de coisas pode ser uma criação no "mundo mental" do falante e do ouvinte, e então ser apropriadamente descrito por uma predicação. Aqui destacamos que os usos linguísticos é que autorizam uma predicação a designar uma criação no "mundo mental”, ou seja, essa abstração não será criação individual, à parte de usos.

Um estado de coisas é, portanto, alguma coisa sobre a qual afirmamos ocorrer, situar-se, ou permanecer em algum mundo. Ele pode ser localizado no tempo e no espaço, pode durar certo tempo, pode ser visto, ouvido, ou de alguma outra forma percebido.

A partir da predicação nuclear, a inteira estrutura da cláusula pode ser construída, ascendendo em níveis, o que se dará pelas especificações concedidas por operadores gramaticais " $\pi$ " e satélites lexicais " $\sigma$ " apropriados para cada nível. Operadores fornecem distinções que são expressas gramaticalmente na língua na qual a predicação se encontra, enquanto satélites são modificadores com expressão lexical. Satélites comumente coincidem com "modificadores adverbiais". No primeiro nível, o estado de coisas nuclear é qualificado por operadores $(\pi 1)$ e satélites de predicado $(\sigma 1)$, os quais fornecem especificação quanto ao tipo de estado de coisas designado. Uma distinção aspectual tal qual "Progressivo" seria um exemplo de um operador de predicado, e os advérbios de modo, tal qual cuidadosamente, seriam exemplo de satélite de predicado. Ambos qualificam o estado de coisas nuclear, resultando na predicação central, que pode ser assim representada:

(3) [Progressivo [escrever (João) (uma carta) $]$ (cuidadosamente)

'João (estava) escrevendo uma carta cuidadosamente. ' ${ }^{4}$

No próximo nível, o estado de coisas qualificado, pode ser localizado no espaço e no tempo por operadores $(\pi 2)$ e satélites $(\sigma 2)$ da predicação. Podemos localizar o estado de coisas designado por (3) espacial e temporalmente do seguinte modo:

(4) [Presente [Progressivo [escrever (João) (uma carta)] (cuidadosamente) $]$ (na biblioteca) $]$

'João está cuidadosamente escrevendo uma carta na biblioteca.' ${ }^{5}$

Um elemento que designa "Presente" representa um significado gramatical para localização temporal, indicando a coincidência entre o tempo da fala e o tempo do estado de coisas descrito ${ }^{6}$. Registramos, aqui, que tempo e aspecto, em muitos casos, imbricam-se, não sendo possível delimitar uma marca linguística só para tempo. Um constituinte como "na biblioteca", por sua vez, representa um significado lexical para localização do estado de coisas no espaço. Pela adição, portanto, de um operador de predicado "Presente" e de um satélite locativo "na biblioteca" à predicação central (4), situamos o estado de coisas antes apenas qualificado também no tempo e no espaço. O resultado é a chamada predicação estendida, que designa um estado de coisas qualificado e localizado.

No nível 2, portanto, dá-se por completa a parte descritiva ou representacional da estrutura da cláusula. $\mathrm{O}$ estado de coisas a ser comunicado está descrito, qualificado e situado. No próximo nível, explica Dik, o Falante pode agora especificar a atitude dele quanto ao estado de coisas. Essa especificação pode ser feita por meio de operadores e satélites proposicionais, ambos designativos de avaliações atitudinais subjetivas ou modais da parte do Falante. Por exemplo, (4) pode ser assim modalizado:

\footnotetext{
4. [Prog [write (John) (a letter)] (carefully)

'John (was) writing a letter carefully.' (DIK, 1997a, p. 51)

$5[$ Pres [Prog [write (John) (a letter)] (carefully)] (in the library)

'John is carefully writing a letter in the library.' (DIK, 1997a, p. 52)

6 Lembramos aqui que o presente também pode ser utilizado em referência a passado e futuro.
} 
(5) ¿Possibilidade [Presente [Progressivo

[escrever (João) (uma carta)]

(cuidadosamente)] (na livraria)] (Até onde eu sei)]

'Até onde eu sei, João pode estar cuidadosamente escrevendo uma carta na biblioteca.' ${ }^{7}$

O operador proposicional "Possibilidade" indica que o Falante julga o estado de coisas como possível. O satélite (até onde eu sel) fornece um dado sobre a qualidade da informação transmitida pelo falante. $\mathrm{O}$ resultado é a proposição, designativa de um fato possível.

Proposições podem ser motivos de surpresa ou de dúvida, podem ser mencionadas, negadas, rejeitadas e relembradas. A veracidade ou falsidade delas pode ser afirmada. Podemos agora afirmar que uma predicação, designativa de um estado de coisas, pode ser construída numa estrutura de ordem mais elevada: a proposição, a qual designa um "conteúdo proposicional" ou um "fato possível".

Retornando à cláusula, Dik prossegue a análise da construção Até onde eu sei, João pode estar cuidadosamente escrevendo uma carta na biblioteca. Diz o estudioso que a estrutura em (5) não propicia uma análise completa dessa construção, pois a análise não contemplou o status de ato de fala ou a força ilocucionária da cláusula como um todo. Assim, resta-nos dizer que essa sentença em apreciação é declarativa, não interrogativa ou imperativa. Assume Dik que os itens marcados pela força ilocucionária são tipicamente proposições, não predicações: nós declaramos ou interrogamos conteúdos proposicionais, não estados de coisas. Em segundo lugar, a força ilocucionária da sentença em análise é propiciada por um significado gramatical, não lexical: é a forma da sentença acrescida de entonação que nos informa ser a sentença afirmativa. Dessa forma, chegamos à seguinte análise da sentença:

(6) ¿Declaração [Possibilidade [Presente [Progressivo

[escrever (João) (uma carta)]

(cuidadosamente) $]($ na biblioteca $)]($ até onde eu sei) $\left.] \sigma 4^{4}\right]^{8}$

O satélite ilocucionário $(\sigma 4)$ também pode ser especificado, nesse caso por algum modificador adverbial o qual, de algum modo, modifica ou especifica o valor da cláusula como um todo. Francamente seria um bom exemplo desse tipo de satélite, uma vez que ele designa como aquele que fala se sente quanto ao conteúdo expresso pela cláusula. Assim, temos:

(7) ¿Declaração [Possibilidade $\sqsubset$ Presente [Progressivo

[escrever (João) (uma carta)]

(cuidadosamente)] (na biblioteca)] (até onde eu sei)] (francamente)]

\footnotetext{
7 [Poss $\sqsubset$ Pres $\sqsubset$ Prog

[write (John) (a letter)]

(carefully)] (in the library)] (as far as I know)]

'As far as I know, John may be carefully writing a letter in the library.' (DIK, 1997a, p.52).

$8[$ Decl $\sqsubset$ Poss $\sqsubset$ Pres $\sqsubset$ Prog

[write (John) (a letter)]

(carefully)] (in the library)] (as far as I know) $\sigma$ 4] (DIK, 1997a, p.53).
} 
'Francamente, até onde eu sei, João pode estar cuidadosamente escrevendo uma carta na biblioteca.' 9

Assim como podemos construir uma proposição de uma predicação estendida, podemos obter um frame ilocucionário de uma proposição, resultando numa cláusula que designa um ato de fala (no caso em análise, um ato de fala declarativo) que concerne à proposição. Essa contém uma predicação estendida, que foi construída de uma predicação central, a qual, por sua vez, contém uma predicação nuclear definida por um predicado, que, por seu turno, foi preenchido por um apropriado número de termos.

Felizmente, salienta Dik, nem todas as cláusulas são complexas como a (7). Muitos operadores e até todos os satélites podem permanecer não especificados. Assim, podemos ter estruturas como a seguinte:

(8) a. João riu.

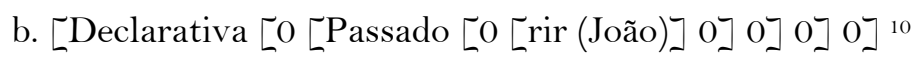

Os elementos vazios são importantes até mesmo para essa estrutura, por indicarem as posições de operadores e satélites que, em uma dada circunstância, podem ser especificados, e indicarem valores “neutros”, uma vez não especificados.

Explicando a importância da compreensão da cláusula em camadas, Dik destaca que essa organização, para efeito de descrição, permite-nos especificar, corretamente, o escopo dos operadores e satélites em diferentes níveis. Por exemplo, se o operador ilocucionário Declarativo pertence ao nível 4, ele terá como escopo toda a cláusula, isto é, a proposição e tudo mais abaixo dela. Por sua vez, um operador de predicado como Passado terá como escopo a predicação central, incluindo os predicados e termos dessa predicação. Em síntese: a cláusula designa um ato de fala, a proposição um fato possível, a predicação um estado de coisas e o predicado propriedade e relação entre termos.

De acordo com o modelo proposto por Dik, a tradicional tripartição das modalidades em dinâmica (concernente às capacidades intrínsecas ou adquiridas), deôntica (ligada ao eixo conceptual da conduta, concernente ao que é legal, moral ou socialmente permitido) e epistêmica (ligada ao eixo conceptual do conhecimento, concernente ao que se conhece sobre o mundo propriamente dito) é contemplada com base em três níveis funcionais presentes na cláusula, a saber: o inerente, o objetivo e o subjetivo.

Estabelece-se, assim, na GF, uma tipologia que versa acerca das seguintes modalidades: modalidade inerente (que contempla os usos modais dinâmicos e alguns usos modais deônticos), modalidade objetiva (que contempla todos os usos deônticos não inerentes e os usos epistêmicos objetivos), modalidade subjetiva (que contempla os usos epistêmicos subjetivos [que serão chamados de epistemológicos e bulomaicos] e os usos evidenciais [inferenciais, citativos, experienciais]).

Tomando como escopo a $1^{\mathrm{a}}$ camada da estrutura da cláusula, os modalizadores configuram a modalidade inerente. Essa concerne a todos os significados linguísticos por meio dos quais um sujeito pode caracterizar as relações entre um participante e a realização de um estado de coisas no qual ele está envolvido. As distinções modais inerentes podem consistir na afirmação da habilidade ou disposição de um participante realizar o estado de coisas (poder, estar habilitado para/ desejar, estar disposto a) ${ }^{11}$ ou no questionamento quanto a se o participante é obrigado (deve, tem de) ${ }^{12}$ ou se a ele é permitido (pode, é permitido) ${ }^{13}$ realizar o estado de coisas.

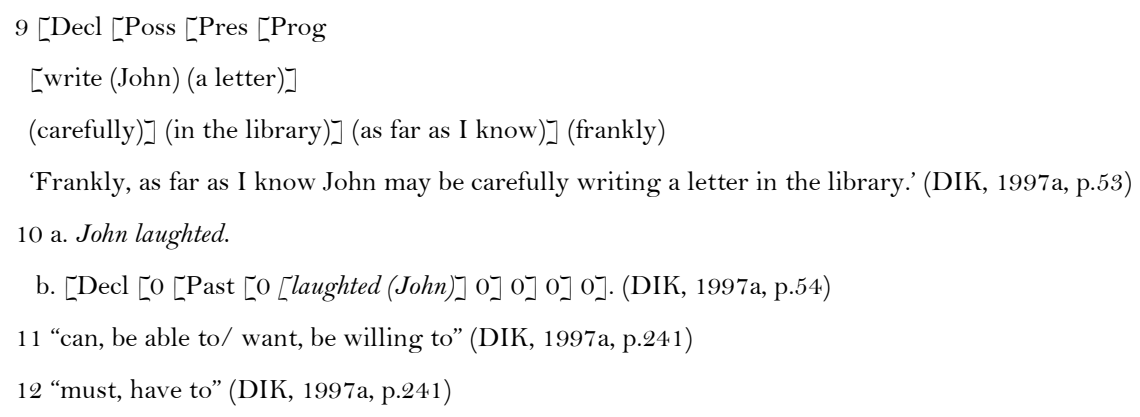


Tomando como escopo a $2^{\mathrm{a}}$ camada da estrutura da cláusula, os modalizadores configuram a modalidade objetiva. Essa concerne à avaliação do falante sobre a probabilidade de ocorrência de um estado de coisas em termos do que sabe sobre estado de coisas em geral. A modalidade objetiva é subdividida em duas subáreas: (i) Modalidade objetiva epistêmica, por meio da qual o falante avalia a factualidade/realidade de um estado de coisas em termos do seu conhecimento dos estados de coisas em geral, (ii) Modalidade objetiva deôntica, por meio da qual o falante avalia a factualidade/realidade de um estado de coisas em termos de um sistema de normas moral, legal ou social. Os valores epistêmicos são "certo - provável - possível - improvável impossível." ${ }_{14}$ Por sua vez, os valores deônticos são "obrigatoriedade - aceitabilidade - permissão inaceitabilidade - proibição." 15

Tomando como escopo a $3^{\text {a }}$ camada da estrutura oracional, os modalizadores configuram a modalidade subjetiva. Esta concerne ao comprometimento do falante quanto à verdade da proposição enunciada. Por meio dos modais subjetivos, o falante assume responsabilidade pessoal pelo conteúdo da proposição e assinala o grau de certeza que tem sobre o conteúdo que enuncia. Os valores subjetivos são "certeza, probabilidade possibilidade - incerteza quanto à verdade do que se afirma." ${ }^{16}$ A modalidade subjetiva é subdividida em duas subáreas: (i) Modalidade subjetiva epistêmica, por meio da qual a falante expressa seu comprometimento pessoal com a verdade do que enuncia, (ii) Modalidade evidencial, por meio da qual o falante expressa seu comprometimento com a qualidade da proposição enunciada, em termos de como ele obteve dada informação: por meio de uma inferência de uma evidência externa (Inferencial), por meio de uma experiência pessoal (Experiencial), ou através do relato de outrem (Reportativa, Citativa). Na modalidade subjetiva, a fonte da avaliação do falante é uma opinião pessoal (é opinião pessoal do falante que $\mathrm{X}$ é certo/ provável/ possível) ou uma volição (o falante deseja/ espera que X se realize). Na modalidade evidencial, a fonte da proposição enunciada é a experiência (o falante conclui X com base na sua experiência prévia pessoal), a inferência (o falante concluiu X com base nas evidências disponíveis) ou a informação proveniente de outrem ( $\mathrm{O}$ falante declara que ouviu $\mathrm{X}$ de outra pessoa).

Dik (1997a) assinala que, embora as noções semânticas de certeza, probabilidade e possibilidade também digam respeito à modalidade objetiva, a qual toma como escopo a $2^{\text {a }}$ camada oracional, a diferença é que, no caso $d a$ modalidade objetiva, a avaliação é apresentada como independente da opinião pessoal do falante. Por sua vez, na modalidade subjetiva, a afirmação é expressa como restrita à opinião pessoal do falante. Aponta Dik que uma razão para essa distinção entre modalidades objetiva e subjetiva é a possibilidade de combinação entre elas. Assim, destaca o pesquisador que, em línguas nas quais há a distinção entre modais objetivos e subjetivos/evidenciais manifesta por meio de verbos, esses geralmente se combinam de modo que os modais subjetivos/evidenciais tomam como escopo expressões em que o modal objetivo faz-se presente. O exemplo citado pelo autor é em turco, retirado de Hengeveld (1989). Transcrevemos o exemplo na sequência:

(9) Gel - me - meli - ymis - siniz (come - neg - necess - infer - 2pl) ${ }^{17}$

Para efeito de compreensão, esse exemplo é traduzido pelo autor para o inglês, o qual equivale a "It seems (inferencial) you ought (objective deontic) not to come." Assinalamos que a tradução do inglês para o português, por nós realizada, também evidencia a correlação entre modais subjetivos/evidenciais e objetivos postulada por Dik. Teríamos: "Parece que (inferencial) você não deve (deôntico) vir."

Em suma, no modelo tradicional da Gramática Funcional, modelo funcional de análise da sentença, a distinção entre as modalidades - Inerente, Objetiva e Subjetiva - dá-se em correlação com os diferentes níveis funcionais na estrutura da cláusula. Nesse modelo, portanto, a modalidade deôntica não é entendida como subjetiva. Em outras palavras, a modalidade deôntica não estaria no exercício da função interpessoal.

No modelo da GF, haveria margem para o entendimento da modalidade deôntica em função subjetiva (interpessoal)? No subtópico seguinte, consideramos, em linhas gerais, a proposta de Vestraete (2004).

\footnotetext{
13 "may, be allowed to" (DIK, 1997a, p.241)

14. “Certain - Probable - Possible - Improbable - Impossible” (DIK, 1997a, p.242)

15 “Obrigatory - Acceptable - Permissible - Unacceptable - Forbidden” (DIK, 1997a, p.242)

16 “Certain - Probable - Possible - Improbable - Impossible” (DIK, 1997a, p.242)

17 “Certain - Probable - Possible - Improbable - Impossible” (DIK, 1997a, p.242)
} 


\section{ENTRE A GRAMÁTICA FUNCIONAL (GF) E A GRAMÁTICA DISCURSIVO-FUNCIONAL (GDF): A PROPOSTA DE VERSTRAETE PARA A MODALIDADE DEÔNTICA}

O texto de Verstraete (2004) integra uma coletânea de trabalhos que se voltam para o modelo de Gramática Funcional de Dik (1997) com a intenção de torná-lo apto a contemplar as funções das unidades linguísticas nos usos que delas são feitos em contextos sociais específicos. Propõe Verstraete (2004) que os modais deônticos podem assumir três funções: a inerente, a objetiva e a subjetiva. Ilustra o estudioso essas funções por meio dos seguintes exemplos:

(10) “'Eu preciso ver Maria'. 'Eu disse a você, ela parece sonolenta. Profundamente sonolenta.' 'Posso ver por mim mesmo?’ 'Você não pode’.” 18 - função subjetiva.

(11) Há uma crise, ele deve agir agora. ${ }^{19}$ - função subjetiva.

(12) Mas o Ramadan significa mais do que privação física. Ele envolve obrigações morais e espirituais também. Os seguidores devem se refrear de maus pensamentos, palavras e ações. ${ }^{20}$ - função objetiva.

(13) Para lançar em órbita um objeto, a aceleração deve alcançar algo em torno de 17.500 milhas por hora em direção horizontal e deve alcançar uma altitude de mais de 100 milhas. ${ }^{21}$ - função inerente.

Segundo análise de Verstraete (2004), nos exemplos (10) e (11), a função dos modais é expressar o comprometimento do falante com a proibição e a obrigação expressas, respectivamente, pelos modais poder $e$ dever. Nesses exemplos, o falante é a fonte da qual emana, respectivamente, a proibição e a obrigação. São admitidas paráfrases tais quais: "Eu não permito a você ver Maria" e "Eu o obrigo a agir". Em exemplos como o (12), por outro lado, não há a expressão do comprometimento do falante com a obrigação assinalada pelo modal, pois ele não é a fonte da qual emana a obrigação. Não se admite, portanto, a paráfrase "Eu quero que os seguidores do Ramadan se refreiem...”. O que há é a menção a uma obrigação particular, sem, necessariamente, o comprometimento do falante quanto a ela. Já em exemplos como o (13), o modal não expressa uma obrigação originária de uma fonte deôntica, mas apenas denota a necessidade que é inerente à situação.

Verstraete (2004) propõe que exemplos como (10) e (11) sejam analisados como subjetivos, em paralelo com a modalidade epistêmica. Por sua vez, propõe que exemplos como (12) sejam interpretados como objetivos e que exemplos como (13) sejam interpretados como inerentes, em função de sua similaridade com os modais dinâmicos de habilidade e volição. Destaca o pesquisador que, em exemplos como (10) e (11), o falante está agindo interpessoalmente. Assim, a modalidade deôntica pode ser tão subjetiva quanto a epistêmica, com a seguinte diferença: o comprometimento não concerne à verdade da proposição, mas à desejabilidade das ações.

Pelo que compreendemos dos exemplos citados por Vestraete (2004), o comprometimento com a desejabilidade de ações concerne ao que é esperado pelo falante. Assim, em (10), o falante espera que a proibição por ele instaurada seja acatada, estando particularmente interessado que assim ocorra. Do mesmo modo que, em (11), o falante espera que a obrigação por ele instaurada seja cumprida, e ele tem particular interesse nesse cumprimento. Nesse sentido, ambos os exemplos devem ser analisados como motivados pelo interpessoal, não pelo representacional. Por sua vez, (12) e (13), não suscitam expectativa pessoal dos falantes quanto às obrigações instauradas, apenas relatam ao ouvinte as referidas obrigações. $\mathrm{O}$ exemplo (12) deve ser analisado, portanto, como motivado pelo nível representacional, pois há uma fonte que instaura a obrigação, enquanto o exemplo (13) deve ser analisado como motivado pela natureza inerente da própria cláusula em razão da ausência de uma fonte da obrigação.

\footnotetext{
18 "I need to see Izzy", I said. "I told you, she's sound asleep. Deeply asleep." "May I see for myself?" "You may not, you shit-sucking liar!" (VERSTRAETE, 2004, p.253)

19 There is a crisis and he must act now. (VERSTRAETE, 2004, p.253)

20 But Ramadan means more than just physical deprivation. It has spiritual and moral obligations, too. Followers must refrain from bad thoughts, words and actions, perform special acts of charity and spend even more time than usual in worship. (VERSTRAETE, 2004, p.253)

21 But to reach orbit an object must accelerate to a speed of about 17,500 miles per hour in a horizontal direction; and it must reach an altitude of more than 100 miles, in order to be clear of the atmosphere. (VERSTRAETE, 2004, p.253)
} 
A nosso ver, Verstraete (2004) aplica o entendimento de Lyons (1977) sobre modalidade deôntica subjetiva versus modalidade deôntica objetiva aos três níveis funcionais presentes na cláusula, conforme proposta do modelo de Dik.

Para Lyons (1977), a modalidade deôntica subjetiva caracteriza-se pelo comprometimento pessoal do falante com o valor deôntico instaurado, com o que também concorda Verstraete (2004). Lyons (1977) caracteriza também a modalidade deôntica objetiva pelo não comprometimento pessoal do falante com o valor deôntico instaurado; nesse caso, o falante pode apenas reportar-se a um valor (o que, a nosso ver, coaduna-se com o entendimento de Verstraete sobre a modalidade deôntica em função objetiva) ou apenas afirmar sua existência (o que, a nosso ver, coaduna-se com o entendimento de Verstraete sobre a modalidade deôntica em função inerente).

Interessante salientar que, ao ponderar acerca da categoria modalidade, Lyons (1977) afirma que a sentença modalizadora deôntica expressa uma proposição, mas não uma proposição que descreve um ato. Por não descrever um ato, mas um estado de coisas a ser obtido caso o ato em questão seja levado a termo, as sentenças modalizadoras deônticas não constituem enunciados sobre os quais se possam afirmar seu valor de verdade ou falsidade. Embora nesse aspecto Lyons (1977) e Dik (1997) concordem, Lyons admite a existência da modalidade deôntica subjetiva, com base no critério do comprometimento pessoal do falante com o valor semântico instaurado pela sentença deôntica.

O modelo de gramática proposto por Dik (1997) adota, como parâmetro funcional para a compreensão da subjetividade, o escopo da cláusula sobre o qual recai o modal. Por isso, esse critério de escopo não contempla o uso desse subtipo modal em contextos sociais específicos, nos quais é possível perceber intenções do falante quanto às expressões modais deônticas.

Em 2008, publicou-se um novo modelo teórico de Gramática Funcional, a Gramática Discursivo-Funcional, que visa à adoção do ato discursivo como unidade de análise. No tópico seguinte, discutiremos como o subtipo modal deôntico é tratado nessa nova versão de gramática funcional: a modalidade deôntica passa a ser contemplada em exercício da função interpessoal?

\section{PROBLEMAS EPISTEMOLÓGICOS}

Pode-se definir a GDF como a sucessora da GF. Segundo Hengeveld e Mackenzie (2008, p.2), a GDF pode ser definida mais concisamente como uma teoria "que procura entender como as unidades linguísticas são estruturadas em termos do mundo que elas descrevem e das intenções comunicativas com que elas são produzidas". ${ }^{22}$ Assumindo o ato discursivo como unidade de análise, o discurso passa a ser na GDF o "suporte" das unidades linguísticas de níveis mais baixos. A GDF se inicia com a formulação da intenção do falante para finalizar com a realização da expressão linguística (modelo top-down). Já a GF se inicia com a seleção de itens lexicais para, em seguida, expandir gradualmente a estrutura subjacente da oração (modelo bottom-up). ${ }^{23}$

A organização top-down do modelo é justificada pelos proponentes da GDF como motivada pela certeza de que quanto mais o modelo de gramática espelhar o processamento individual da linguagem mais efetivamente dará conta do fenômeno linguístico. De acordo com os autores, estudos psicolinguísticos, tais quais os de Levelt (1989), provam que a produção da linguagem verbal é um processo top-down, o qual tem início com intenções comunicativas e chega a seu termo com a articulação da expressão linguística. Assim,

\footnotetext{
22 "FDG aims to understand how linguistic units are structured in terms of the world they describe and the communicative intentions with which they are produced, [...].”(HENGEVELD \& MACKENZIE, 2008,p. 2)

23 Aqui se faz necessária uma ressalva. Embora o modelo de análise da cláusula presente na Gramática Funcional proposta por Dik seja bottom-up, conforme exposto, Dik concebe um modelo de interação verbal que entende os usos linguísticos como partindo da intenção do falante à codificação linguística. Segundo depreendemos da leitura de Dik (1997a, p. 8), ao nos engajarmos em um ato de interação verbal, quando na posição de falantes (ou escritores), produzimos expressão linguística em função de uma dada intenção, da informação pragmática de que dispomos e da antecipação que fazemos de qual seja a possível interpretação daquele com o qual interagimos. Por seu turno, quando na posição de destinatários, embasamos nossa interpretação na expressão linguística produzida, na informação pragmática de que dispomos e na nossa conjectura acerca da possível intenção do falante, procurando reconstruí-la. É exatamente por alicerçar sua proposta de análise gramatical em modelo de interação pela linguagem verbal que tem como base a intenção comunicativa, que nos parece incongruente a exclusão da modalidade deôntica de uma função subjetiva.
} 
Hengeveld e Mackenzie caracterizam a GDF como uma teoria sobre gramática que procura refletir evidências psicolinguísticas em sua arquitetura.

A GDF distingue duas operações na construção de enunciados: Formulação e Codificação. A Formulação diz respeito às regras que determinam as representações pragmáticas e semânticas que são válidas em uma língua. A Codificação diz respeito às regras que convertem essas representações pragmáticas e semânticas em representações morfossintáticas e fonológicas. A operação de formulação envolve três processos interligados: a seleção de estruturas apropriadas para o nível Interpessoal e o Representacional, a inserção de lexemas apropriados nessas estruturas e a aplicação de operadores, simbolizando as distinções gramaticais requeridas na língua em análise. A operação de codificação também envolve três processos: a seleção de moldes apropriados para o nível Morfossintático e o Fonológico, a inserção de morfemas gramaticais livres e presos e a aplicação de operadores que atuam no processo de articulação do output gramatical.

A GDF distingue quatro níveis de organização da linguagem: Interpessoal, Representacional, Morfossintático e Fonológico. Dois níveis para formulação (o nível Interpessoal e o Representacional, para análises, respectivamente, pragmática e semântica) e dois para codificação (o nível Morfossintático e o Fonológico). Justificam os autores os quatro níveis de organização linguística propostos em decorrência da possibilidade de ocorrer, em cada um deles, a possibilidade de referência anafórica. Consideram os proponentes da GDF os seguintes exemplos:

(14) A. Saia daqui!

B. Não fale comigo desse modo! ${ }^{24}$

(15) A. Há muitos sinais de trânsito nessa cidade.

B. Eu não tinha percebido isso. ${ }^{25}$

(16) A. Eu comi chuletas de cordero ontem à noite.

B. É deste modo que você diz 'costeleta de cordeiro' em Espanhol? 26

(17) A. Eu comi /tfu'letasdekor'dero/ ontem à noite.

B. Não seria isso '/ tfu'letasdeĐor'dero/? ${ }^{27}$

Em (14B), o elemento anafórico desse refere-se à estratégia comunicativa escolhida por A, a qual é indicativa da presença de um nível interpessoal na base da representação de (14A). Em (15B), o elemento anafórico isso se refere à situação no mundo exterior descrita dentro de $(15 \mathrm{~A})$. Essa referência puramente semântica evidencia que a estrutura subjacente de (15A) contém um nível representacional de organização. Por sua vez, as referências anafóricas em $(16 \mathrm{~B})$ e (17B) são de natureza metalinguística. Em (16B), deste não se refere à entidade descrita por chuletas de cordero, mas ao sintagma 'chuletas de cordero' como tal, tomado como uma unidade morfossintática. Concluem os autores da GDF que esse sintagma está presente na estrutura subjacente e, assim, pode funcionar como um antecedente para a referência anafórica. De maneira semelhante, ocorre a referência em $(17 \mathrm{~B})$, a única diferença é que o antecedente é uma unidade fonológica.

\footnotetext{
24. A. Get out of here!

B. Don't talk to me like that! (HENGEVELD; MACKENZIE, 2008, p.5)

25 A. There are lots of traffic lights in this town.

B. I didn't notice that. (HENGEVELD; MACKENZIE, 2008, p.5)

26 A. I had chuletas de cordero last nignt.

B. Is that how you say 'lamb chops' in Spanish? (HENGEVELD; MACKENZIE, 2008, p.5)

27 A. I had /tfu'letasdekor'dero/ last nignt.

B. Shouldn't that be '/ tfu'letasdeӨor'dero/'? (HENGEVELD; MACKENZIE, 2008, p.5)
} 
Com base nessa linha argumentativa, Hengeveld e Mackenzie (2008) concluem que a representação subjacente de uma sequência linguística contém quatro níveis de organização: um Interpessoal (pragmática), um Representacional (semântica), um Morfossintático (morfossintaxe) e um Fonológico (fonologia). Destacam os autores que a natureza dos quatro níveis é puramente linguística, o que é assegurado, inclusive, para os níveis Interpessoal e Representacional, pois, embora esses dois níveis descrevam a língua em termos de suas funções e significados, essa descrição dá-se somente se essas funções e significados estiverem gramaticalmente codificados na gramática de uma língua.

Dentro desta nova versão teórica, a classificação das categorias modais não mais se correlaciona a camadas oracionais, mas aos quatro níveis de organização da linguagem supramencionados. São parâmetros para a classificação das categorias modais: o alvo e o domínio da avaliação de uma distinção modal.

Pelo primeiro parâmetro, o alvo da avaliação de uma distinção modal, três tipos de modalidades podem ser distinguidas: Modalidade orientada para o participante, Modalidade orientada para a proposição, Modalidade orientada para o evento.

O alvo da avaliação dos modais orientados para o participante é o participante em um evento descrito no enunciado. Concerne à relação entre um participante de um evento (ou à propriedade de) e a potencial realização desse evento. Como exemplo, os autores citam "Você está habilitado a nadar (a participar deste curso)"28 . Notamos que o alvo da avaliação dessa distinção modal é o participante deste evento, representado no enunciado pelo pronome "você". A possibilidade de ocorrência desse evento é avaliada pelo falante como dependente da capacidade intrínseca do participante.

O alvo da avaliação dos modais orientados para a proposição é a parte do enunciado que representa as visões e crenças dos falantes. Concerne à especificação do grau de comprometimento do falante em relação à proposição que ele apresenta. Como exemplo, os autores citam "Provavelmente/ evidentemente/ indubitavelmente/ Sheila está doente." ${ }_{29}$ Nesse exemplo, notamos que provavelmente, evidentemente e indubitavelmente são modificadores de um conteúdo proposicional 'Sheila está doente', ou seja, de um construto mental que pode ser avaliado em termos de seu valor de verdade.

O alvo da avaliação dos modais orientados para o evento é o próprio evento descrito no enunciado. Concerne à avaliação do status de realidade de um evento, sem que o falante assuma responsabilidade por essa avaliação. Como exemplo, os autores citam a construção discutida em Lyons (1977) "Certamente, ele deve ter esquecido." 30 Nesse exemplo, temos uma expressão modal orientada para a proposição (certamente) e uma expressão modal orientada para o evento (deve ter). Por meio do advérbio orientado para a proposição, o falante compromete-se com a verdade do conteúdo proposicional 'ele deve ter esquecido', o qual contém o verbo modal orientado para o evento, que descreve a existência da possibilidade de ocorrência do estado de coisas 'ele esqueceu'. Embora os dois julgamentos presentes no exemplo sejam aparentemente desarmônicos, não há contradição, uma vez que os dois julgamentos pertencem a dois diferentes níveis ${ }^{31}$ : o falante exprime sua certeza sobre a existência de uma possibilidade objetiva.

A modalidade orientada para o participante e a orientada para o evento são chamadas de objetivas, e a orientada para a proposição é chamada de subjetiva. Nas duas primeiras, compreende-se que o falante emite julgamentos, sem, contudo, assumir responsabilidades pelo teor de seus enunciados, daí serem ditas objetivas. Na terceira, compreende-se que o falante emite julgamentos comprometendo-se pessoalmente com eles, daí serem ditas subjetivas.

Pelo segundo parâmetro, o domínio da avaliação de uma distinção modal, ou seja, a perspectiva da qual a avaliação é feita, cinco tipos de modalidades podem ser distinguidas: Modalidade facultativa (ou dinâmica), Modalidade deôntica, Modalidade volitiva, Modalidade epistêmica e Modalidade evidencial.

\footnotetext{
28 "you have to be able to swim (to participate in this course)." (HENGEVELD; MACKENZIE, 2008, p.213 - exemplo 213)

29 "Probably/ evidently/ undoubtedly Sheila is ill." (HENGEVELD; MACKENZIE, 2008, p.151 - exemplo 113)

30 "Certainly, he may have forgotten.” (HENGEVELD; MACKENZIE, 2008, p.174 - exemplo 239)

31 Aqui não mais estamos nos referindo a níveis da cláusula. Neste novo modelo teórico, conforme considerado, quatro níveis de organização linguística são contemplados: dois níveis correlacionam-se à formulação linguística (o Interpessoal e o Representacional) e dois outros níveis à codificação da formulação linguística (o Morfossintático e o Fonológico). Como ponderam Hengeveld e Mackenzie (2008, p.3); em um modelo de orientação discursiva, a cláusula é apenas uma das opções que o falante pode usar na codificação da formulação do discurso.
} 
A Modalidade facultativa (ou dinâmica) diz respeito às capacidades intrínsecas ou adquiridas. Destacam Hengeveld e Mackenzie (2008) que, em algumas línguas, traça-se distinção entre habilidade intrínseca (estar habilitado para) e adquirida (saber como). Destacam os autores que o espanhol realiza essa distinção: habilidades intrínsecas são expressas por meio do modal "poder" (be able to), enquanto as adquiridas o são por meio do verbo "saber" (know to) em seu uso modal.

A Modalidade deôntica diz respeito ao que é legal, moral, socialmente admitido (ex: "Eu devo comer"32). Nesse exemplo, impelido por uma necessidade, o falante instaura obrigação que recai sobre si mesmo, e o faz por meio de um verbo auxiliar modal "dever".

A Modalidade volitiva diz respeito ao que é desejável. Citam os autores o exemplo "João deseja ser jovem de novo" ${ }^{33}$. Ao citarem esse exemplo, que é de uma modalidade volitiva voltada para o participante do evento, Hengeveld e Mackenzie (2008) aproveitam para justificar o motivo da opção pela escolha do termo "modalidade voltada para o participante", sobre o qual há pouco versamos, ao invés de voltada para o agente, expressão utilizada por vários estudiosos da modalidade, como Lyons (1977). Segundo os autores, a expressão "voltada para o agente" não é feliz, pois sugere que apenas participantes caracterizados pelo traço semântico [+ controle] em estados de coisas dinâmicos podem estar sob o escopo desse tipo de modalização, o que não seria o caso de "João" em "João deseja ser jovem de novo." Assim, fazem os autores a opção por um termo que consideram mais neutro - "voltada para o participante". ${ }^{34}$

A Modalidade epistêmica diz respeito ao que se conhece sobre o mundo propriamente dito (ex: "Provavelmente, Sheila está doente" ${ }^{35}$ ). Dentro de um contexto real de uso de língua, a ausência injustificada, por exemplo, de uma funcionária à empresa em que trabalha, poderia suscitar comentários do tipo "Provavelmente X está doente." Ao assim se expressar, aquele que enuncia o faz embasado, por exemplo, no conhecimento que tem da assiduidade da funcionária, ou de algum sinal de saúde debilitada que percebeu na funcionária etc. Enfim, do conhecimento que tem em particular (caso conheça a realidade da pessoa sobre a qual fala) e em geral (não se falta ao trabalho sem um motivo sério).

A Modalidade evidencial diz respeito à fonte da informação contida na sentença (ex: "Aparentemente, ele está provavelmente vivendo no Condado de Lanark, na Escócia." $\left.{ }^{36}\right)$. O advérbio em itálico indica uma inferência daquele que fala, com base em algo que tenha percebido ou de uma informação que lhe fora dada.

A combinação dos três alvos da avaliação de uma distinção modal com os cinco domínios permite-nos conceder dez subtipos modais.

Os modais dinâmicos orientados para o participante descrevem a habilidade de um participante envolver-se no evento designado no enunciado. Por sua vez, os modais dinâmicos orientados para o evento caracterizam eventos em termos das condições físicas ou circunstanciais que permitem a ocorrência desses eventos.

Os modais deônticos orientados para o participante descrevem uma obrigação que recai sobre um participante ou uma permissão para envolver-se no tipo de evento designado pelo enunciado. Por sua vez, os modais deônticos orientados para o evento caracterizam eventos em termos do que é obrigatório ou permitido dentro de algum sistema de convenções moral ou legal. Observa-se que as obrigações expressas por significados da modalidade deôntica orientados para o evento representam regras gerais de conduta, comuns em expressões do tipo "Entrada proibida". No entanto, também se observa que o sentido de

\footnotetext{
32 "I must eat." (HENGEVELD; MACKENZIE, p.213)

33 "John wants to be young again.” (HENGEVELD; MACKENZIE, 2008, p.212)

34. Pela natureza em si da modalidade deôntica, o alvo deôntico caracteriza-se pelo traço semântico [+controle], mesmo que indiretamente. Em construções do tipo "É preciso observar o dia-a-dia da sociedade e trazer as questões para o contraditório e a reflexão." (excerto do discurso proferido pelo Deputado Colbert Martins - Partido do Movimento Democrático Brasileiro - PMDB /Bahia - BA. Data: 15/02/2007. No Grande Expediente da Sessão Ordinária 013.1.53, às 17h21min. Publicação: Diário da Câmara dos Deputados, em 16/02/2007, p. 5007), observamos que não há explicitação do alvo humano sobre o qual recai a obrigação instaurada. O alvo da modalização (ou seja, o foco da construção linguística modalizadora) é, nesse caso, o evento descrito no enunciado. No entanto, é evidente que apenas um alvo é caracterizado pelo traço semântico [+ controle] é que pode, em tempo posterior ao tempo em que a obrigação foi instaurada, levá-la a termo. Ou seja, a expressão "agente”, com sua sugestão de traço semântico [+controle], não é problemático para o estudo da modalidade deôntica, ao menos em português.

35 "Probably Sheila is ill." (HENGEVELD; MACKENZIE, 2008, p.151)

36 “Apparently he is probably living in lanarkshire.” (HENGEVELD; MACKENZIE, 2008, p.152)
} 
obrigação geral pode ser apresentado como construções pessoais, ou seja, as que recaem sobre um participante em particular.

Os modais volitivos orientados para o participante descrevem o desejo do participante de se envolver no evento designado pelo enunciado. Por sua vez, os modais volitivos orientados para o evento caracterizam eventos em termos do que é geralmente desejável ou indesejável. Já os modais volitivos orientados para a proposição caracterizam a atitude volitiva do falante. O falante é a fonte da atitude volitiva.

Os modais epistêmicos orientados para o evento caracterizam eventos em termos de suas (im)possibilidades de ocorrência de acordo com o que se sabe sobre o mundo. Por sua vez, os modais epistêmicos orientados para a proposição caracterizam o grau de (in)certeza do falante em relação ao conteúdo proposicional de seu enunciado.

Os modais evidenciais orientados para a proposição dizem respeito a como a informação apresentada pelo falante chegou ao conhecimento do falante.

Ao término dessa consideração das modalidades no arcabouço da GDF, retornamos à pergunta que suscitamos no parágrafo concludente do segundo subtópico: a modalidade deôntica passa a ser contemplada em exercício da função interpessoal? A resposta é negativa. Um cotejo entre os dois modelos de Gramática Funcional revela que a modalidade deôntica é descartada da função subjetiva em ambos.

\section{A NÃO CONTEMPLAÇÃO DA FUNÇÃO INTERPESSOAL NO ENTENDIMENTO DA MODALIDADE DEÔNTICA NA GF E NA GDF - O CONCEITO DE “FUNCIONAL”}

Como vimos, a GF identifica subtipos da modalidade pela camada oracional sobre a qual incide a expressão linguística modalizadora, enquanto a GDF identifica subtipos da modalidade com base no nível de organização linguística sobre o qual incide a expressão linguística modalizadora. Apesar dessa diferença, há um ponto de convergência entre elas: a camada de escopo da modalidade deôntica é entendida, na GF, como representacional, assim como o é o nível de organização linguística, que serve de escopo para a modalidade deôntica na GDF. Tanto a GF quanto a GDF descartam a possibilidade de subjetividade na modalidade deôntica em decorrência do mesmo parâmetro adotado: a não incidência sobre conteúdos proposicionais.

Neste ponto é preciso deixar claro a separação entre os dois conceitos aqui em questão: "interpessoal" e "representacional". De acordo com Hengeveld e Mackenzie (2008, p.129), a impossibilidade de elementos ocorrerem em um discurso indireto relatado indica seu estatuto interpessoal; por sua vez, a possibilidade de elementos ocorrerem em um discurso indireto relatado indica seu estatuto representacional. Assim, se alguém chamado Pedro nos diz algo do tipo "Francamente, Sheila tem de ser mais profissional e menos passional", provavelmente, reportaríamos a outrem essa fala de Pedro do seguinte modo: "Pedro disse-me que Sheila tem de ser mais profissional e menos passional"; e não do seguinte modo: "Pedro disse-me que francamente Sheila tem de ser mais profissional e menos passional" - a menos que se trate de um discurso literal direto ou de um discurso indireto livre.

Além disso, no caso de rejeição à assertiva "Francamente, Sheila tem de ser mais profissional e menos passional", essa recairia apenas sobre o fato de Sheila ter de ser mais profissional e menos passional, não sobre o "francamente". Assim, o advérbio "francamente" é entendido como elemento funcionalmente pragmático (interpessoal), pois não estabelece uma relação com o mundo exterior, mas atua internamente à situação discursiva. Por sua vez, o auxiliar modal "ter de" é entendido como elemento funcionalmente semântico (representacional), pois concerne ao mundo extralinguístico descrito pela língua.

Neste ponto é necessário retornarmos ao discutido, na introdução, sobre os postulados que, em linhas gerais, costumam ser enunciados na caracterização da perspectiva funcionalista de estudo da linguagem a fim de ponderarmos acerca do conceito "funcional". A afirmação segundo a qual a abordagem funcionalista busca explicar as construções das expressões linguísticas em termos de sua funcionalidade em relação aos modos de utilização das expressões em contextos sociais específicos é condizente com as chamadas perspectivas funcionalistas radicais (ou a elas próximas) de análise gramatical. 
Hengeveld e Mackenzie (2008, p.6-31) apresentam como exemplo de perspectiva funcionalista próxima ao que poderíamos denominar por funcionalismo radical a Gramática Sistêmico-Funcional (GSF), de Halliday e Matthiessen (2004). Embora também seja uma abordagem funcional da estrutura linguística, a GSF é orientada para o uso da linguagem em contextos sociais específicos; enquanto a GDF limita-se a reflexões gramaticais sistemáticas de significados sociais.

Como a GSF toma o texto, não a sentença, como objeto da descrição linguística, ela dever ser, portanto, mais apropriadamente chamada de gramática do discurso na medida em que a análise é derivada do texto. A GDF, por sua vez, não é uma gramática do discurso, pois sua meta é entender as propriedades sistemáticas do que seus autores chamam de Ato Discursivo, definido como a unidade mínima de comunicação.

A GDF também difere da GSF por seu foco nas questões linguísticas correlacionadas à psicologia individual ao invés de na dimensão social da língua em uso, embora reconheça que esses dois aspectos são intimamente conectados, pois a interação social é mediada por aspectos ligados à psicologia individual.

Outro ponto que distingue as duas perspectivas funcionalistas ${ }^{37}$ é a orientação tipológica da GDF, dada sua preocupação com os princípios subjacentes à variação entre as línguas. Já a GSF, por centralizar sua preocupação na descrição de línguas individuais, não viabiliza um aparato tipológico para os resultados linguísticos.

A GDF e a GSF são modelos funcionalistas porque se alicerçam no postulado segundo o qual as propriedades das expressões linguísticas são adaptadas aos objetivos comunicativos que os usuários da língua, em interação com outros usuários, buscam alcançar por meio dessas expressões - base essa que contrapõe ambos os modelos a perspectivas formalistas mais radicais. Mas a GDF, como Hengeveld \& Mackenzie expressam (2008, p.26), ocupa uma posição intermediária entre o funcionalismo radical e o formalismo radical. Em outras palavras, entre o funcionalismo que rejeita a realidade cognitiva da estrutura linguística, tendendo a extrair generalizações indutivas de dados linguísticos particulares, e o formalismo que limita o estudo linguístico ao sistema, de forma totalmente independente dos usos que dele são feitos.

Ao demarcar essa posição intermediária e bem explicitá-la pelo cotejo com a Gramática SistêmicoFuncional, a GDF estabelece para si um conceito do que é funcional que nem sempre é compreendido por seus críticos. Quando se critica a não contemplação da função interpessoal no entendimento da modalidade deôntica na GF e na GDF (sucessora da GF, recorde-se) o que se tem em mente são os modos de atuação desse subtipo modal em contextos sociais específicos de uso das línguas naturais, o que é a proposta de modelos como a GSF. Mas, por estarem interessadas nos significados sociais refletidos nas gramáticas das línguas, a GF e a GDF sustentam-se numa acepção mais abstrata do termo funcional.

Ao procurar entender como as unidades que compõem o sistema linguístico são estruturadas em termos do mundo que elas descrevem, a GF e a GDF propõem que há unidades linguísticas que descrevem o mundo extralinguístico (função representacional) e outras que atuam internamente à situação discursiva (função interpessoal). Em momento algum se afirma que essas unidades com função sistêmica representacional não exercem função interpessoal em contextos sociais específicos, pois isso seria negar a intencionalidade do falante no uso do sistema e significaria voltar-se para uma perspectiva radical de formalismo. O que ocorre, porém, é que os referidos modelos não se propõem ao trabalho com essas unidades em contextos sociais específicos de uso da linguagem.

Ao mesmo tempo em que compreendemos essa acepção do termo funcional - há unidades linguísticas cuja função é de descrição do mundo extralinguístico e há unidades cuja função é de atuação interna à situação discursiva - consideramos que a contemplação de intenções dos falantes, na forma de graus de desejabilidade de ações, por exemplo, como propôs Verstraete (2004), permite trazer para o bojo dessa funcionalidade sistêmica a saudável interlocução com a funcionalidade ligada a contextos específicos de usos.

\footnotetext{
37 À exceção do conceito de Ato Discursivo, as demais distinções postas aqui em destaque neste cotejo entre GDF e GSF também se prestam a estabelecer distinção entre a GF e a GSF.
} 


\section{CONSIDERAÇÕES FINAIS}

A nosso ver, a não contemplação da modalidade deôntica em função subjetiva na GF e na GDF dá-se em decorrência do entendimento do que é o exercício da função subjetiva. A função subjetiva vem sendo compreendida como concernente ao comprometimento do falante - comprometimento esse gramaticalmente marcado - em relação ao valor de verdade do que ele enuncia. A única parte do enunciado, segundo a GF, ou nível de organização linguística, segundo a GDF, que representa as visões e crenças dos falantes, caracterizando-se, portanto, como construto que pode ser avaliado em termos de seu valor de verdade, é a proposição!

Se a função subjetiva for compreendida como concernente também ao comprometimento do falante com a desejabilidade de ações, o modal deôntico poderá ser interpretado como no exercício da função subjetiva, embora não recaia sobre a proposição em termos estruturais. Com essa compreensão do significado de função subjetiva, adequamos o entendimento da modalidade deôntica aos usos reais dessa categoria gramatical. É esse o ponto que defendemos (MENEZES, 2011, 2006). Nesse prisma, na modalidade deôntica orientada para o participante e na orientada para o evento, há emissão de julgamentos, embasados no que se concebe como legal, moral, socialmente admitido, e o falante assume responsabilidades quanto às ações recomendadas (seja pelas ações que o próprio falante recomenda, seja pelas ações que ele apresenta como indesejáveis).

Defendemos que os modais deônticos expressam valores semânticos (obrigatoriedade - aceitabilidade permissão - inaceitabilidade - proibição) com os quais o enunciador pode mostrar-se pessoalmente comprometido ou não. Propomos também, para o entendimento da função subjetiva da modalidade deôntica, que os outros tipos de modalidade propostos na GDF sejam considerados quando tomam como escopo uma expressão linguística que contém modalizador deôntico. Por exemplo, há casos em que um modalizador epistêmico toma como escopo um enunciado que contém um modalizador deôntico, o que evidencia o comprometimento pessoal do falante quanto à desejabilidade de uma ação ou não ação, ao mesmo tempo em que pode atenuar ou reforçar a força do valor semântico instaurado pelo modal deôntico.

\section{REFERÊNCIAS}

DIK, S. The theory of functional grammar. Parte II: Complex and devived constructions (Functional Grammar Series 21) Edited by Kess Hengeveld. Berlin and New York, NY: Mounton de Gruyter, 1997b.

The theory of functional grammar. Parte I: The sctructure of the clause. (Functional Grammar Series 20) 2nd revised edition. Edited by Kess Hengeveld. Berlin and New York, NY: Mounton de Gruyter, $1997 \mathrm{a}$.

HALLIDAY, M.; MATTHIESSEN, C. An introduction to Functional Grammar (3rd revised edition of Halliday 1985). London: Hodder Arnold, 2004.

HENGEVELD, K. Layers and operators in Functional Grammar. Journal of Linguistics, v. 25, n.1, p. 127157 (=WPFG 27 (1988)), 1989.

HENGEVELD, K.; MACKENZIE, J. L. Functional Discourse Grammar: a typologically-based theory of language structure. Oxford: Oxford University Press, 2008.

LEVELT, W. J.M. Speaking. Cambridge, MA: MIT Press, 1989.

LYONS, J. Semantics. Cambridge: Cambridge University Press, v.2, 1977.

MENEZES, L. C. Expressões linguísticas modalizadoras deônticas em função argumentativa: um exercício de análise retórico-funcional. 2011.332p. Tese (Doutorado em Linguística) - Faculdade de Letras, Universidade Federal do Ceará, Fortaleza, 2011.

. A modalidade deôntica na construção da persuasão em discursos políticos. 2006. 122p. Dissertação (Mestrado em Linguística) - Faculdade de Letras, Universidade Federal do Ceará, Fortaleza, 2006.

NEVES, M.H.M. A gramática funcional. São Paulo: Martins Fontes, 1997. 
ERSTRAETE, J.C. The problem of subjective modality in the Functional Grammar model. In:

MACKENZIE, J. L.; GÓMEZ-GONZÁLEZ, M. Á. (Eds.). A new architecture for Functional Grammar (Fuctional Grammar Series 24). Berlin/New York: Mouton de Gruyter, 2004, p. 243-273.

Recebido em 12/o2/13. Aprovado em 19/06/13. 